\title{
Association between integrity of foveal photoreceptor layer and visual acuity in branch retinal vein occlusion
}

\author{
Masafumi Ota, Akitaka Tsujikawa, Tomoaki Murakami, Mihori Kita, Kazuaki Miyamoto, Atsushi \\ Sakamoto, Noritatsu Yamaike, Nagahisa Yoshimura
}

Br J Ophthalmol 2007;91:1644-1649. doi: 10.1136/bjo.2007.118497

See end of article for authors' affiliations

Correspondence to: Akitaka Tsujikawa, Department of Ophthalmology, Kyoto University Graduate School of Medicine, Sakyo-ku, Kyoto 606-8507, Japan; tujikawa@kuhp.kyoto-u.ac. ip

Accepted 1 May 2007 Published Online First 15 May 2007
Aim: To study the correlation between integrity of the photoreceptor layer after resolution of macular oedema (MO) associated with branch retinal vein occlusion (BRVO) and final visual acuity (VA), and to determine prognostic factors for visual outcome.

Methods: We retrospectively studied 46 eyes from 46 patients with resolved MO secondary to BRVO, the foveal thickness of which was less than $250 \mu \mathrm{m}$ at final observation. We assessed the status of the third high reflectance band (HRB) in the fovea using optical coherence tomography (OCT) at final observation, and studied OCT images taken at the initial visit in the hope of identifying a factor that would be prognostic of visual outcome.

Results: No differences were found in initial VA or in foveal thickness between eyes with or without complete third HRB at final observation. However, final VA in eyes without a complete HRB was significantly poorer $(p<0.002)$. Additionally, initial status of the third HRB in the parafoveal area of unaffected retina was associated with final VA; lack of visualisation of the third HRB at $500 \mu \mathrm{m}(p=0.0104)$ or $1000 \mu \mathrm{m}$ $(p=0.0167)$ from the fovea on initial OCT images was associated with poor visual recovery after resolution of the MO.

Conclusion: Integrity of the photoreceptor layer in the fovea is associated with VA in resolved $M O$, and status of the third HRB before treatment might be predictive of visual outcome.
M acular oedema (MO) is the major cause of visual disturbance associated with branch retinal vein occlusion (BRVO). ${ }^{12}$ To date, various treatments have been reported to be effective in reducing $\mathrm{MO}$ associated with BRVO, such as grid laser photocoagulation, ${ }^{13-5}$ pars plana vitrectomy combined with internal limiting membrane peeling ${ }^{6}$ or arteriovenous sheathotomy, ${ }^{7}$ and intravitreal injections of triamcinolone acetonide ${ }^{8-11}$ or bevacizumab. ${ }^{12}$ After successful treatment, resolution of MO often leads to substantial improvement in visual acuity (VA)..$^{138-14}$ Some patients, however, have a poor visual outcome despite complete resolution of the MO. ${ }^{13}$

Optical coherence tomography (OCT) is now used widely to measure quantitatively the retinal thickness in order to monitor the effectiveness of therapy and to confirm resolution of MO. ${ }^{14-}$ ${ }^{25}$ With high resolution and contrast, OCT allows us to evaluate also the status of the third high reflectance band (HRB), which has been reported to show reflection derived from the junction between inner and outer segments of the photoreceptors. ${ }^{15-17}$ Because several investigators have reported that the status of the third HRB in the fovea is related closely to VA in eyes with retinitis pigmentosa ${ }^{17}$ or resolved central serous chorioretinopathy, ${ }^{18}{ }^{19}$ it is attracting a great deal of attention as a possible marker of the integrity of the photoreceptor layer.

Investigators from our laboratory recently reported that, in eyes with BRVO, the integrity of the third HRB is associated with final VA after resolution of MO brought about by treatment with an intravitreal injection of tissue plasminogen activator. ${ }^{14}$ To achieve good visual recovery, restoration of the structure of the photoreceptors to a more physiologic condition would be needed, and not merely reduction of the foveal thickness. In our previous report, however, we did not provide information on the status of the third HRB before treatment. In the current work, we studied the correlation between status of the third HRB and VA in eyes with resolved MO secondary to
BRVO. In addition, we studied the status of the third HRB in the foveal region before treatment and assessed the prognostic factors related to vision after resolution of $\mathrm{MO}$.

\section{PATIENTS AND METHODS}

For this retrospective study, we reviewed the medical records of 46 eyes from 46 patients who had resolved MO associated with BRVO in which the foveal thickness was less than $250 \mu \mathrm{m}$ at final observation. All patients previously had a visual disturbance due to $\mathrm{MO}$ associated with BRVO, and had follow-up of more than 6 months. The ages of the 46 patients ( 19 men and 27 women) ranged from 55 to 82 years (mean (SD) 69.7 (7.4) years). In these 46 eyes, treatments to resolve the MO were as follows: 30 eyes were treated with grid laser photocoagulation, 15 eyes underwent pars plana vitrectomy and 9 eyes received intravitreal or posterior sub-Tenon injections of triamcinolone acetonide. In 19 eyes, a combination of two or more treatments was performed. Eyes treated with tissue plasminogen activator were not included in the current study. For this retrospective study, Institutional Review Board/ Ethics Committee approval was not required.

In all patients, OCT examination at final observation was performed with a third-generation OCT (OCT3; Stratus model 3000, Carl Zeiss, Dublin, California, USA). In most eyes, vertical cross-section OCT scans ( $5 \mathrm{~mm}$ in length) centred on the fovea were used. Integrity of the photoreceptor layer after resolution of MO was examined by evaluating the status of the third HRB. ${ }^{15-17}$ On OCT imaging, the third HRB was identified as a distinct band just above the high reflectance layer of the retinal pigment epithelium-choriocapillaris complex, and in greyscale mode could be detected more readily (fig 1). ${ }^{14}$ Accordingly, we

Abbreviations: $B R V O$, branch retinal vein occlusion; $H R B$, high reflectance band; $M O$, macular oedema; $O C T$, optical coherence tomography; RPE, retinal pigment epithelium; VA, visual acuity 


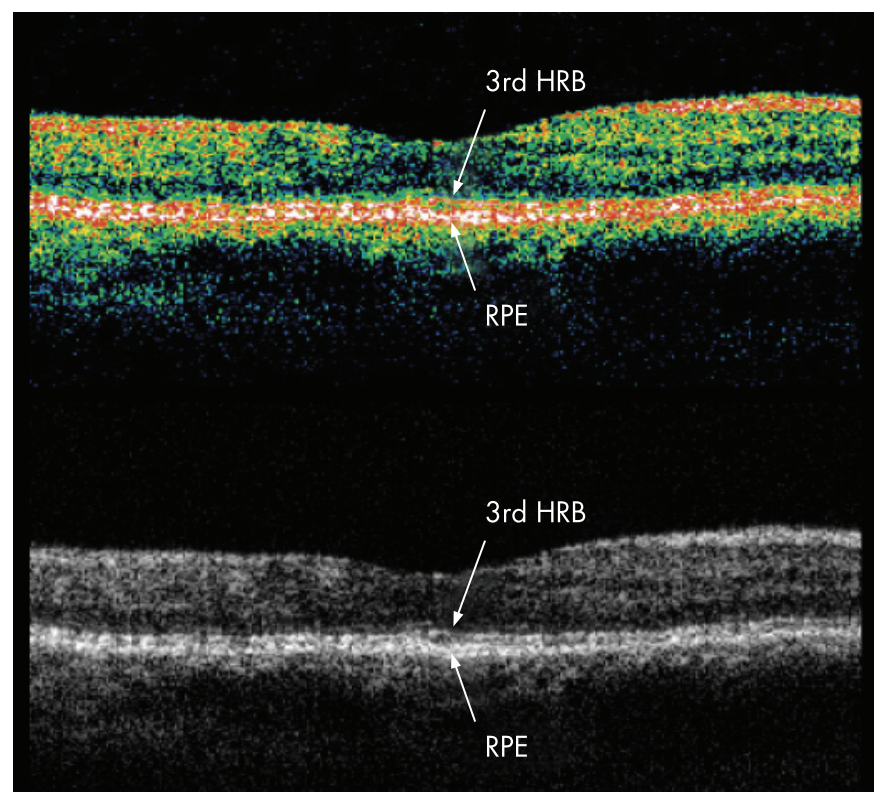

Figure 1 Sectional retinal images of vertical scan of fovea obtained with optical coherence tomography (OCT3; Stratus model 3000) after resolution of macular oedema secondary to branch retinal vein occlusion (BRVO). (A) Pseudocolour OCT image. (B) Monochromatic OCT image. Retina affected by $B R V O$ is shown on the left side of the images. The third high reflectance band (HRB) can be identified more clearly in the monochromatic (greyscale) OCT image. RPE, retinal pigment epithelium.

evaluated the status of the third HRB using the greyscale raw image obtained with the OCT3. In the current study, the evaluation was performed in an unmasked fashion.

At the initial visit, 29 of the 46 eyes were imaged with the OCT3; the other 17 patients were examined with an older version OCT. In the 29 eyes examined with the OCT3, and using greyscale raw images, we examined whether or not the third HRB was detected in the fovea at the initial observation visit. Unfortunately, it was often difficult to determine the status of the foveal third HRB at the initial visit due to retinal thickening and fresh retinal haemorrhage. We also evaluated the status of the third HRB at points 500, 1000 and $1500 \mu \mathrm{m}$ vertically from the fovea, toward the unaffected side of the retina. We investigated the correlation between integrity of the third HRB at the initial visit and the final status of the third HRB in the fovea or visual outcome.

All best-corrected VA measurements were converted to logarithm of the minimum angle of resolution (logMAR) equivalents. All values are presented as mean (SD). VA and the foveal thickness of eyes with and without the third HRB were compared using the Mann-Whitney $U$ test and the

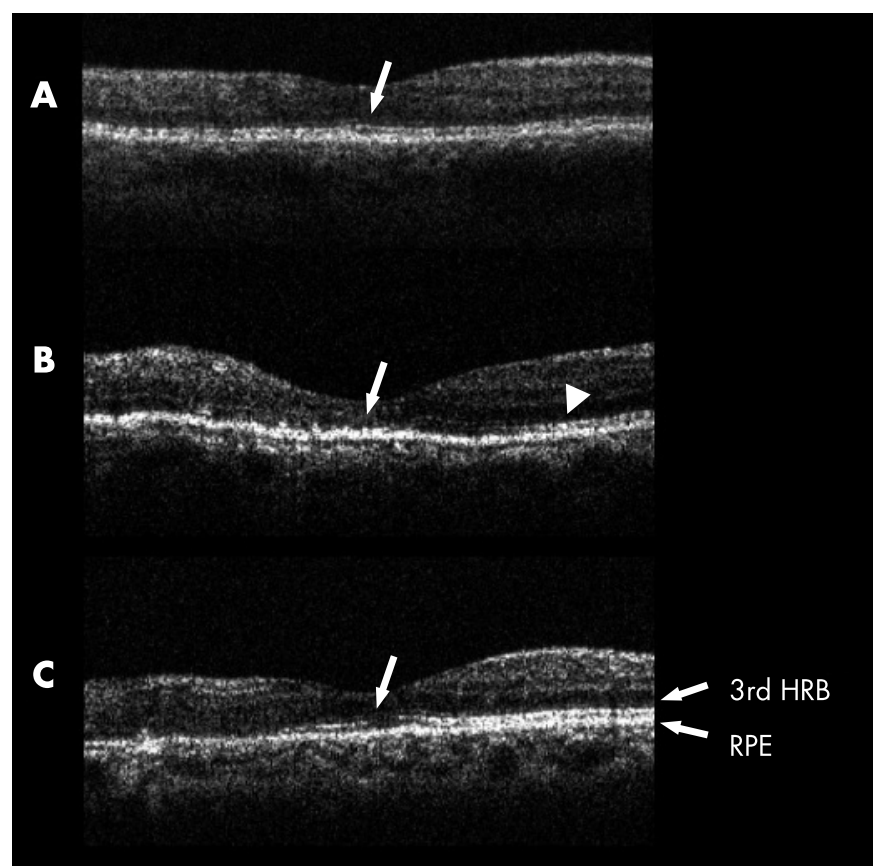

Figure 2 Optical coherence tomography (OCT) images of vertical retinal sections of the fovea obtained at the final visit. Macular oedema secondary to branch retinal vein occlusion (BRVO) is resolved completely in all images. The retina affected by BRVO is shown on the left in all images. Status of the third high reflectance band (HRB) was evaluated with monochromatic (greyscale) OCT images. (A) The third HRB is well preserved in the fovea (arrow). (B) The third HRB is well preserved in the unaffected retina (arrowhead), but is deteriorated in the fovea (arrow) and affected retina. (C) The third HRB is discontinuous in the fovea (arrow), while it is clearly detected in unaffected retina. RPE, retinal pigment epithelium.

Wilcoxon signed-rank test. We studied the correlation between the third HRB status at the initial visit and the final VA using the $X^{2}$ test. A p value of less than 0.05 was considered to be statistically significant.

\section{RESULTS}

At the final observation visit, 21 eyes (46\%) showed a complete third HRB in the fovea (HRB(+) group), while 25 eyes $(54 \%)$ showed a lack of or an incomplete third HRB in the fovea $(\mathrm{HRB}(-)$ group); 16 of the latter $25(64 \%)$ had no third HRB in the fovea, and 9 of the 25 (36\%) had a discontinuous third HRB (fig 2).

Table 1 shows the clinical characteristics of the two groups. At the initial visit, no statistically significant differences were found in age or in foveal thickness. Mean VA at the initial visit was somewhat poorer in the $\mathrm{HRB}(-)$ group than in the $\mathrm{HRB}(+)$

Table 1 Patient characteristics by integrity of the third HRB at the final visit

\begin{tabular}{lllr}
\hline & HRB $(+) \mathbf{n = 2 1}$ & HRB $(-) \mathbf{n = 2 5}$ & $\mathbf{p ~ V a l u e ~}$ \\
\hline Age (years) & $69.9(7.8)$ & $69.6(7.1)$ & 0.733 \\
Gender (men/women) & $12 / 9$ & $7 / 18$ & 0.046 \\
Systemic hypertension & 12 & 13 & 0.897 \\
LogMAR VA at initial visit & $0.40(0.34)$ & $0.55(0.35)$ & 0.092 \\
Foveal thickness at initial visit $(\mu \mathrm{m})$ & $466(129)$ & $516(165)$ & 0.453 \\
Duration of symptoms before first treatment (months) & $3.0(1.7)$ & $4.4(3.6)$ & 0.309 \\
LogMAR VA at final visit & $0.05(0.13)$ & $0.32(0.29)$ & $<0.001$ \\
Foveal thickness at final visit $(\mu \mathrm{m})$ & $198(32)$ & $182(32)$ & 0.082 \\
Duration of follow-up (months) & $25.9(19.7)$ & $20.8(14.8)$ & 0.326 \\
Duration of persistent MO (months) & $10.4(5.5)$ & $15.0(11.9)$ & 0.078 \\
\hline
\end{tabular}

$H R B$, high reflectance band; $H R B(+)$, eyes with third $H R B$ in the fovea; $H R B(-)$, eyes without third $H R B$; $\log M A R$, logarithm of the minimum angle of resolution; $\mathrm{VA}$, visual acuity; $\mathrm{MO}$, macular oedema. 
Table 2 Correlation between status of third HRB at initial visit examined at 500, 1000 and $1500 \mu \mathrm{m}$ from fovea and final status of third HRB

\begin{tabular}{|c|c|c|c|}
\hline \multirow[b]{2}{*}{ Third HRB status at initial visit } & \multicolumn{2}{|c|}{ Third HRB status at final visit } & \multirow[b]{2}{*}{ p Value } \\
\hline & $\overline{\mathrm{HRB}(+)}$ & HRB $(-)$ & \\
\hline $\begin{array}{l}\text { In fovea: } \\
\text { Present } \\
\text { Absent }\end{array}$ & $\begin{array}{l}3 \\
9\end{array}$ & $\begin{array}{r}1 \\
16\end{array}$ & 0.141 \\
\hline $\begin{array}{l}\text { At } 500 \mu \mathrm{m} \text { from fovea: } \\
\text { Present } \\
\text { Absent }\end{array}$ & $\begin{array}{r}10 \\
2\end{array}$ & $\begin{array}{r}2 \\
15\end{array}$ & $<0.001$ \\
\hline $\begin{array}{l}\text { At } 1000 \mu \mathrm{m} \text { from fovea: } \\
\text { Present } \\
\text { Absent }\end{array}$ & $\begin{array}{r}11 \\
1\end{array}$ & $\begin{array}{l}9 \\
8\end{array}$ & 0.0033 \\
\hline $\begin{array}{l}\text { At } 1500 \mu \mathrm{m} \text { from fovea: } \\
\text { Present } \\
\text { Absent }\end{array}$ & $\begin{array}{r}12 \\
0\end{array}$ & $\begin{array}{r}15 \\
2\end{array}$ & 0.218 \\
\hline
\end{tabular}

$\mathrm{HRB}(+)$, eyes with third high reflectance band (HRB) in the fovea; HRB(-), eyes without third HRB in the fovea.

group, but the difference was not statistically significant $(p=0.092)$. At the final visit, mean foveal thickness in both groups had decreased significantly, but there was no statistically significant difference in final foveal thickness between the two groups. In accordance with the reduction of retinal thickness, the mean final VA in both groups improved significantly $(\mathrm{p}<0.001$ in each group). Final VA in the $\mathrm{HRB}(+)$ group, however, was significantly better than that in the HRB $(-)$ group $(\mathrm{p}<0.001)$.

In the study described herein, 29 eyes from 29 patients with MO secondary to BRVO were examined with the OCT3 at the initial visit. We next studied the initial status of the foveal third HRB in these eyes. The third HRB could only be detected completely in the fovea in $4(14 \%)$ of the 29 eyes at the initial visit. In the other 25 eyes that did not show a complete third HRB in the fovea at the initial examination, 9 (36\%) showed a complete third HRB at the final visit (table 2), and $14(56 \%)$ had a final VA of at least 20/32 (table 3). Initial status of the third HRB in the fovea was not prognostic of either the final status of the foveal third HRB or of visual outcome.

In eyes that had OCT3 images taken at the initial visit, we further evaluated the status of the third HRB at points 500, 1000 and $1500 \mu \mathrm{m}$ vertically from the fovea, toward the unaffected side of the retina (fig 3), with the hope of predicting final status of the third HRB in the fovea and final VA. At a point $500 \mu \mathrm{m}$ from the fovea, initial OCT3 images showed a complete third HRB in $12 / 29$ eyes $(41 \%)$ and an incomplete third HRB in $17 / 29$ (59\%) eyes (fig 4). Of the 12 eyes with a complete third HRB at the initial visit, 10 (83\%) had a complete third HRB in the fovea at the last examination. In the 17 eyes with incomplete or no third HRB at the initial visit, $15(88 \%)$ never showed a complete third HRB $(p<0.001)$. In the same 12 eyes with a complete third HRB at the first visit, 10 (83\%) had vision of 20/32 at the final visit, while of the 17 eyes with an incomplete third HRB at the first visit, only $6(35 \%)$ had a final VA of 20/32 ( $p=0.0104)$.

Similarly, at a point $1000 \mu \mathrm{m}$ from fovea, initial OCT3 images showed a complete third HRB in 20/29 (69\%) eyes and an incomplete third HRB in 9/29 (31\%) eyes. Initial status of the HRB at a point $1000 \mu \mathrm{m}$ from the fovea correlated significantly with the final HRB status at the fovea $(p=0.0033)$ and with visual outcome $(p=0.0167)$. However, at a point $1500 \mu \mathrm{m}$ from fovea, the third HRB was detected completely in 27 (93\%) of 29 eyes. This detection was not correlated with final HRB status in the fovea or with visual outcome $(p=0.218$ and $p=0.104)$.

\section{DISCUSSION}

MO associated with BRVO appears as a thickening of the sensory retina due to leakage from the affected retinal capillaries. To date, various treatments have been reported to

Table 3 Correlation between status of third HRB at initial visit examined at 500, 1000 and $1500 \mu \mathrm{m}$ from fovea and final VA

\begin{tabular}{|c|c|c|c|}
\hline \multirow[b]{2}{*}{ Third HRB status at initial visit } & \multicolumn{2}{|c|}{ VA at final visit } & \multirow[b]{2}{*}{ p Value } \\
\hline & $\geqslant 20 / 32$ & $<20 / 32$ & \\
\hline $\begin{array}{l}\text { In the fovea: } \\
\text { Present } \\
\text { Absent }\end{array}$ & $\begin{array}{r}2 \\
14\end{array}$ & $\begin{array}{r}2 \\
11\end{array}$ & 0.823 \\
\hline $\begin{array}{l}\text { At } 500 \mu \mathrm{m} \text { from fovea: } \\
\text { Present } \\
\text { Absent }\end{array}$ & $\begin{array}{r}10 \\
6\end{array}$ & $\begin{array}{r}2 \\
11\end{array}$ & 0.0104 \\
\hline $\begin{array}{l}\text { At } 1000 \mu \mathrm{m} \text { from fovea: } \\
\text { Present } \\
\text { Absent }\end{array}$ & $\begin{array}{r}14 \\
2\end{array}$ & $\begin{array}{l}6 \\
7\end{array}$ & 0.0167 \\
\hline $\begin{array}{l}\text { At } 1500 \mu \mathrm{m} \text { from fovea: } \\
\text { Present } \\
\text { Absent }\end{array}$ & $\begin{array}{r}16 \\
0\end{array}$ & $\begin{array}{r}11 \\
2\end{array}$ & 0.104 \\
\hline
\end{tabular}



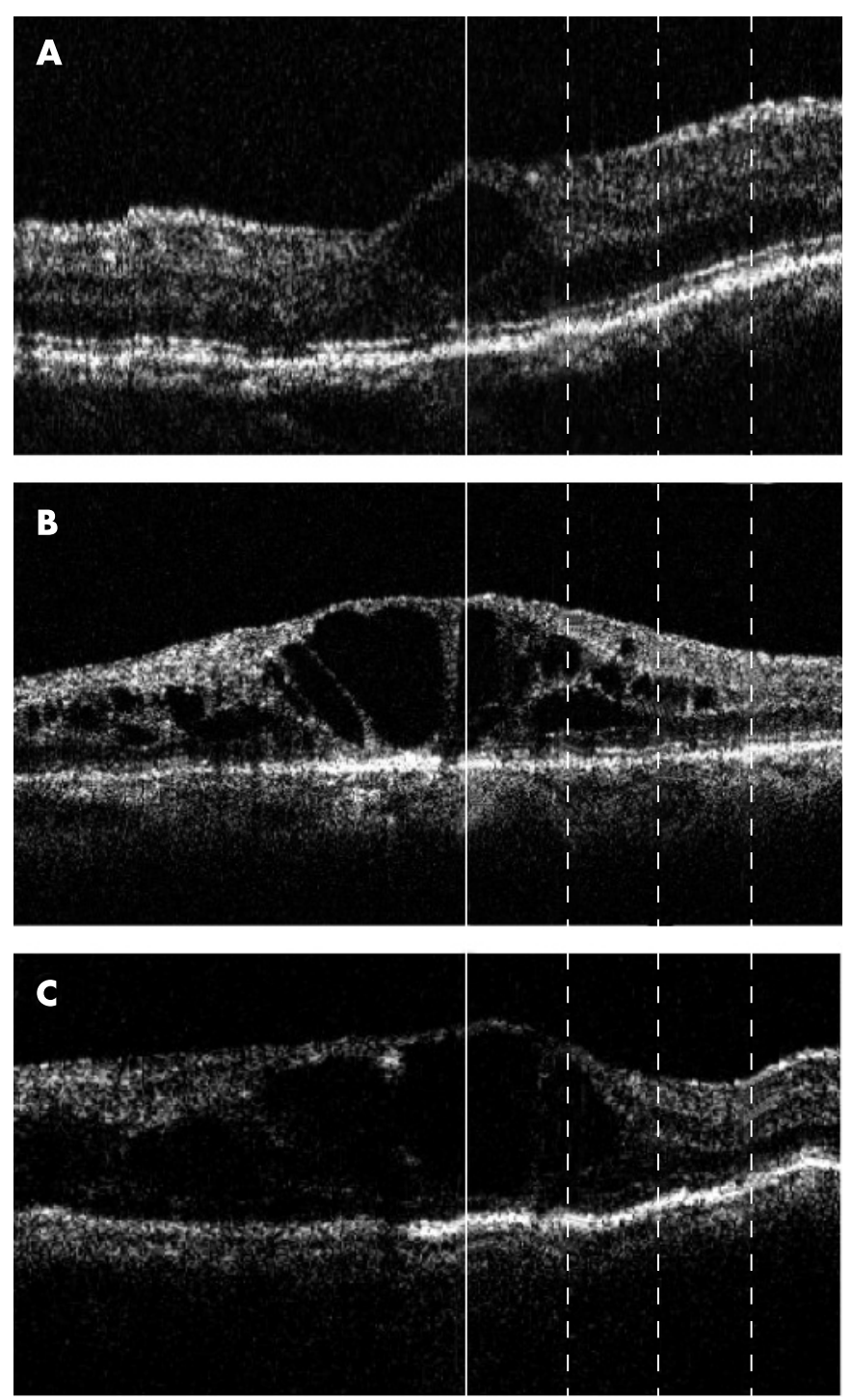

Figure 3 Monochromatic (greyscale) images of optical coherence tomography (OCT) obtained at the initial visit. All images show macular oedema secondary to branch retinal vein occlusion (BRVO). The retina affected by BRVO is on the left in all images. The vertical line at the centre of each image represents the location of the fovea. The three dotted lines represent points at 500, 1000 and $1500 \mu \mathrm{m}$ from the fovea, from the left, respectively. (A) The third high reflectance band (HRB) is clearly visible at all points. (B) The third HRB is not detected beneath the fovea or at $500 \mu \mathrm{m}$ from the fovea, but does appear at the $1000 \mu \mathrm{m}$ and $1500 \mu \mathrm{m}$ points. (C) The third HRB can be detected only at $1500 \mu \mathrm{m}$ from the fovea.

successfully reduce the retinal thickening and restore foveal function. ${ }^{1-13}$ It is generally believed that the decrease in foveal thickness is what leads to improvement in VA. ${ }^{1-4}{ }^{6-13}$ In a clinical setting, however, some patients achieve only poor or limited improvement in VA despite complete resolution of the MO. ${ }^{14}$ Although foveal thickness in all eyes in the current study was less than $250 \mu \mathrm{m}$, final VA after resolution of the MO ranged from $20 / 200$ to $20 / 16$. The reasons for this marked variance in final VA is controversial, but integrity of the foveal photoreceptor layer might explain the difference in final VA after resolution of MO.

OCT has recently become a part of routine clinical examination of patients with macular disease, and allows us to evaluate the morphologic changes that take place in MO. ${ }^{14}{ }^{17-25}$ In a recent report, Costa et al ${ }^{15}$ suggested the significance of two highly reflective layers at the level of the outer retina in OCT images. They suggested that the inner layer, which is identical to the third HRB reported in the current study, could not be detected in damaged outer retina. Similarly, Sandberg et al ${ }^{17}$ reported that decreased VA in eyes with retinitis pigmentosa is associated with declining visualisation of the third HRB in the fovea. In eyes with central serous chorioretinopathy, Eandi et $a l^{18}$ and Piccolino et al ${ }^{19}$ reported that changes within the foveal photoreceptor layer were associated with decreased vision. Based on previous reports and on our findings, ${ }^{14}{ }^{15}$ 17-19 integrity of the foveal retinal photoreceptor layer is associated with good VA, while incomplete visualisation of the third HRB in the fovea could suggest deterioration or disorganisation of photoreceptor cells.

In the current study, status of the third HRB of the 46 eyes was assessed after resolution of MO. While all eyes showed a reduction in foveal thickness (to less than $250 \mu \mathrm{m}$ ) at the final visit, VA in eyes with an incomplete or no third HRB remained poor. Recently, we reported a similar correlation between status of the third HRB and VA in BRVO-induced MO treated with an intravitreal injection of tissue plasminogen activator. ${ }^{14}$ The reasons why the final status of the third HRB varies from eye to eye remain unclear. It is possible that more severe ischaemia in the foveal photoreceptor cells during the acute or chronic phase of BRVO might lead to significant photoreceptor cell death, resulting in the lack of the third HRB. It is also possible that more severe swelling in the foveal photoreceptor layer during the acute phase of BRVO might result in significant disarrangement of photoreceptor cells even after resolution of the MO. In such a disarranged photoreceptor layer, the third HRB might not be detected as a reflective line.

It would be of great value to be able to predict, before treatment, final integrity of the photoreceptor layer and visual outcome. In the current study, we evaluated the status of the third HRB before treatment, and in only 4 of 29 eyes could the third HRB be detected in the foveal region at the initial patient visit. It is possible that the severe retinal haemorrhage and thickened neurosensory retina due to the leakage from BRVO weakened the signal intensity of the outer retinal layers, making it impossible to detect reflection from the junction of inner and outer segments. It is also possible that the photoreceptor layer is swollen due to leakage from the affected capillaries, so the improper alignment of inner/outer segments could not be detected as a reflective line. Histologic reports seem to support the second explanation, as cystoid spaces in MO associated with BRVO have reportedly been seen often in the outer nuclear and plexiform layers, and extensive MO often affects the photoreceptor layer in the fovea, with resultant photoreceptor dysfunction and cell loss. ${ }^{26}$ We could not make this determination, however, due to the limitations of OCT3 imaging.

MO due to BRVO extends often to unaffected retina beyond the fovea as the leakage from the affected capillaries becomes severe. While the fovea is often blocked with fresh retinal haemorrhage, only limited haemorrhage extends to the unaffected retina. Accordingly, in an attempt to predict the final status of the foveal photoreceptor layer and visual outcome, we examined the initial status of the third HRB at points 500, 1000 and $1500 \mu \mathrm{m}$ vertically from the fovea and progressing toward the unaffected portion of retina. When leakage from the capillaries in the affected area was severe, retinal swelling often extended to some of the evaluation points in unaffected portions of the retina. Based upon evaluation of many OCT images, this extension of retinal swelling is seen primarily in the outer retina. The photoreceptor layer is swollen due to leakage from the affected capillaries, so the improper alignment of inner/outer segments could not be detected as a reflective line. In such cases, the foveal photoreceptor layer 


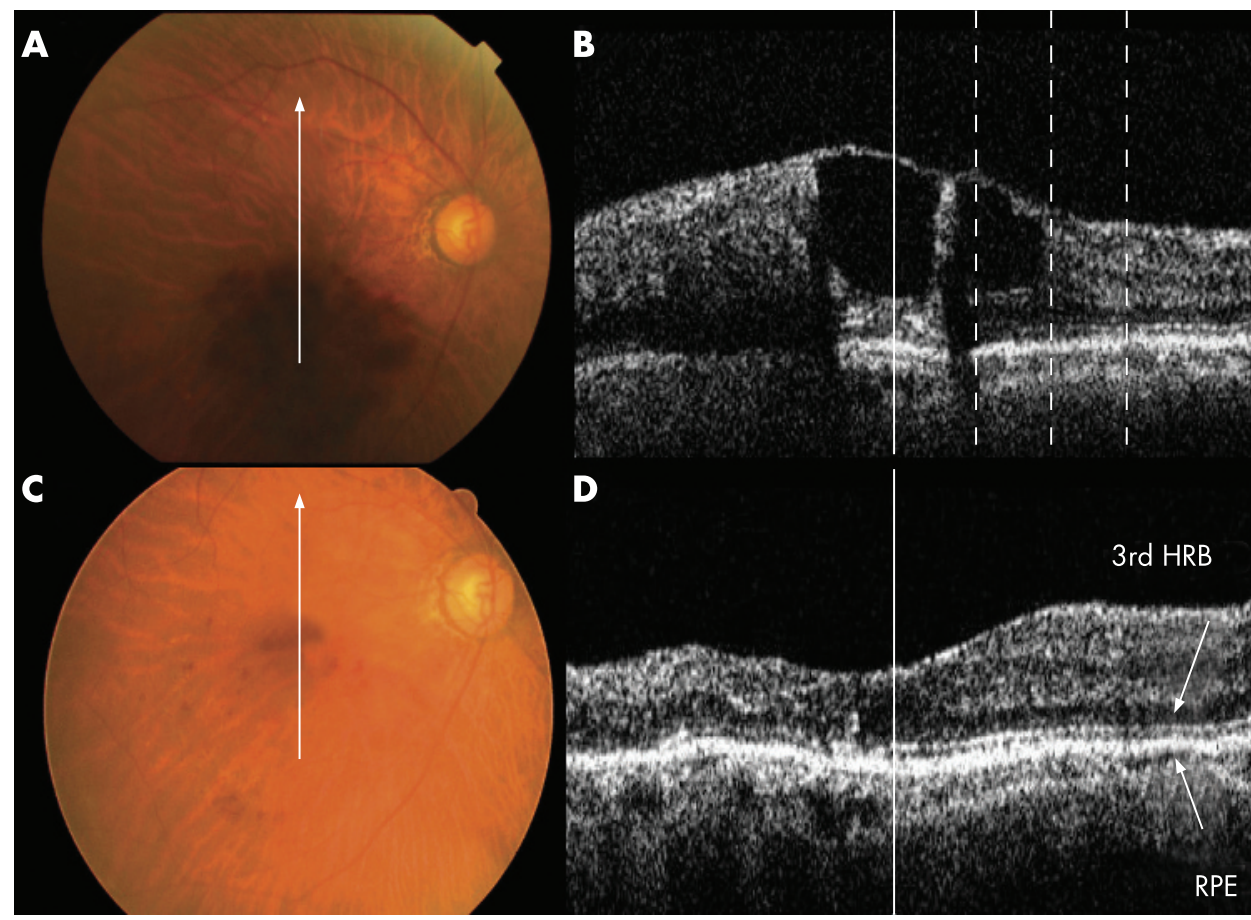

Figure 4 An 82-year-old woman with branch retinal vein occlusion (BRVO) accompanied by macular oedema $(\mathrm{MO})$ with a 1-month history of decreased visual acuity in the right eye, which was $20 / 50$ at the initial visit. (A) Fundus photograph shows extensive retinal haemorrhage associated with BRVO. (B) Monochromatic optical coherence tomography (OCT) image of the fovea was made at the initial visit. The vertical solid line represents the location of the fovea. The three dotted lines represent points 500, 1000 and $1500 \mu \mathrm{m}$ from the fovea, from the left, respectively. MO was prominent with large cystoid spaces and a foveal thickness of $464 \mu \mathrm{m}$. The third HRB cannot be detected in the fovea but is well visualised at other measurement points. The patient was treated with grid laser photocoagulation in the right eye. (C) Fundus photograph at the final visit shows minimal retinal haemorrhage. (D) OCT image at the final visit shows the $M O$ to be completely resolved. Foveal thickness is now $165 \mu \mathrm{m}$. The third HRB is well preserved in the fovea and visual acuity was $20 / 25$. The vertical solid line represents the location of the fovea.

might be affected severely at the initial visit, resulting in an incomplete third HRB even after resolution of $\mathrm{MO}$ - and poor visual outcome.

Limitations of the current study are its retrospective nature and small sample size. Our findings suggest, however, that OCT images could provide information on the foveal photoreceptor layer and visual prognosis in eyes with resolved MO associated with BRVO by use of the third HRB as a landmark. Although the initial status of the third HRB in the fovea could not be evaluated due to retinal haemorrhage, we can assume the final status of the third HRB in the fovea from the initial status of the parafoveal third HRB. The current study showed that resolution of MO leads in many cases to significant improvement in VA. However, when the third HRB in the parafoveal region is incomplete at the initial visit, visual recovery, even after successful treatment of the MO, could still be limited. Further prospective studies, especially with the use of high resolution images of Fourier-domain OCT, are necessary to elucidate which eyes with MO associated with BRVO can be expected to have marked improvement in VA after resolution of the MO.

\section{Authors' affiliations}

Masafumi Ota, Akitaka Tsujikawa, Tomoaki Murakami, Mihori Kita, Kazuaki Miyamoto, Atsushi Sakamoto, Noritatsu Yamaike, Nagahisa Yoshimura, Department of Ophthalmology, Kyoto University Graduate School of Medicine, Kyoto, Japan

Competing interests: None declared.

\section{REFERENCES}

1 The Branch Vein Occlusion Study Group. Argon laser photocoagulation for macular edema in branch vein occlusion. Am J Ophthalmol 1984;98:271-82.

2 Glacet-Bernard A, Coscas G, Chabanel A, et al. Prognostic factors for retinal vein occlusion: prospective study of 175 cases. Ophthalmology 1996; 103:551-60.

3 Esrick E, Subramanian ML, Heier JS, et al. Multiple laser treatments for macular edema attributable to branch retinal vein occlusion. Am J Ophthalmol 2005: 139:653-7.

4 Ohashi $\mathrm{H}$, Oh H, Nishiwaki $\mathrm{H}$, et al. Delayed absorption of macular edema accompanying serous retinal detachment after grid laser treatment in patients with branch retinal vein occlusion. Ophthalmology 2004;111:2050-6.
5 Arnarsson A, Stefansson E. Laser treatment and the mechanism of edema reduction in branch retinal vein occlusion. Invest Ophthalmol Vis Sci 2000:41:877-9

6 Mandelcorn MS, Nrusimhadevara RK. Internal limiting membrane peeling for decompression of macular edema in retinal vein occlusion: a report of 14 cases. Retina 2004;24:348-55

7 Horio N, Horiguchi M. Effect of arteriovenous sheathotomy on retinal blood flow and macular edema in patients with branch retinal vein occlusion. Am J Ophthalmol 2005;139:739-40.

8 Tsujikawa A, Fujihara M, Iwawaki T, et al. Triamcinolone acetonide with vitrectomy for treatment of macular edema associated with branch retinal vein occlusion. Retina 2005;25:861-7.

9 Karacorlu M, Ozdemir H, Karacorlu SA. Resolution of serous macular detachment after intravitreal triamcinolone acetonide treatment of patients with branch retinal vein occlusion. Retina 2005;25:856-60.

10 Cekic O, Chang S, Tseng JJ, et al. Intravitreal triamcinolone injection for treatment of macular edema secondary to branch retinal vein occlusion. Retina 2005;25:851-5

11 Chen SD, Sundaram V, Lochhead J, et al. Intravitreal triamcinolone for the treatment of ischemic macular edema associated with branch retinal vein occlusion. Am J Ophthalmol 2006;141:876-83.

12 Iturralde D, Spaide RF, Meyerle CB, et al. Intravitreal bevacizumab (Avastin) treatment of macular edema in central retinal vein occlusion: a short-term study. Retina 2006;26:279-84

13 Murakami T, Takagi $\mathrm{H}$, Kita $M$, et al. Intravitreal tissue plasminogen activator to treat macular edema associated with branch retinal vein occlusion. Am J Ophthalmol 2006;142:318-20.

14 Murakami T, Tsujikawa A, Ohta M, et al. Photoreceptor status after resolved macular edema in branch retinal vein occlusion treated with tissue plasminogen activator. Am J Ophthalmol 2007;143:171-3.

15 Costa RA, Calucci D, Skaf M, et al. Optical coherence tomography 3: automatic delineation of the outer neural retinal boundary and its influence on retinal thickness measurements. Invest Ophthalmol Vis Sci 2004:45:2399-406.

16 Chen TC, Cense B, Miller JW, et al. Histologic correlation of in vivo optical coherence tomography images of the human retina. Am J Ophthalmol 2006;141:1165-8.

17 Sandberg MA, Brockhurst RJ, Gaudio AR, et al. The association between visual acuity and central retinal thickness in retinitis pigmentosa. Invest Ophthalmol Vis Sci 2005;46:3349-54.

18 Eandi CM, Chung JE, Cardillo-Piccolino F, et al. Optical coherence tomography in unilateral resolved central serous chorioretinopathy. Retina 2005;25:417-21.

19 Piccolino FC, de la Longrais RR, Ravera G, et al. The foveal photoreceptor layer and visual acuity loss in central serous chorioretinopathy. Am J Ophthalmol 2005:139:87-99.

20 Spaide RF, Lee JK, Klancnik JK Jr, et al. Optical coherence tomography of branch retinal vein occlusion. Retina 2003;23:343-7.

21 Lerche RC, Schaudig U, Scholz F, et al. Structural changes of the retina in retinal vein occlusion - imaging and quantification with optical coherence tomography. Ophthalmic Surg Lasers 2001;32:272-80.

22 Ozdek SC, Erdinc MA, Gurelik G, et al. Optical coherence tomographic assessment of diabetic macular edema: comparison with fluorescein angiographic and clinical findings. Ophthalmologica 2005;219:86-92.

23 Antcliff RJ, Stanford MR, Chauhan DS, et al. Comparison between optical coherence tomography and fundus fluorescein angiography for the detection of 
cystoid macular edema in patients with uveitis. Ophthalmology 2000; 107:593-9.

24 Markomichelakis NN, Halkiadakis I, Pantelia E, et al. Patterns of macular edema in patients with uveitis: qualitative and quantitative assessment using optical coherence tomography. Ophthalmology 2004;111:946-53.
25 Voo I, Mavrofrides EC, Puliafito CA. Clinical applications of optical coherence tomography for the diagnosis and management of macular diseases. Ophthalmol Clin North Am 2004;17:21-31.

26 Tso MOM. Pathology of cystoid macular edema. Ophthalmology 1982;89:902-15.

\section{EDUCATION}

Answers

From questions on page 1582

\section{(1) Describe the ultrasound biomicroscopic findings}

Ultrasound biomicroscopy (UBM) revealed an elongated dome shaped irido ciliary mass that extended from the posterior aspect of the peripheral iris to the ciliary body (asterisk ( ${ }^{*}$ ) in fig 1B). The mass was centred at $7 \mathrm{o}^{\prime}$ clock meridian and measured $8.5 \mathrm{~mm}$ circumferentially, $5.0 \mathrm{~mm}$ anteroposteriorly and $2.4 \mathrm{~mm}$ in height. An incidental iris pigment epithelial cyst was also observed (fig 1B arrow). Note anterior displacement of the peripheral iris and amorphous deposits in the angle.

\section{(2) What is the diagnosis based on fine needle aspiration biopsy sample?}

The cells are large and columnar with prominent nucleoli. The cytological appearance is consistent with adenocarcinoma. (Papanicolaou stain, 100x). No particular site of origin of the tumour can be identified by cell morphology in this sample. The cytological sample was insufficient to perform immunoperoxidase stains. (B) Histopathology of the enucleated globe. Adenocarcinoma in the angle and ciliary body (haematoxylineosin stain, 20x). The tumour cells were weakly positive for CK 20 and strongly positive for CK7, suggesting adenocarcinoma arising in the gastrointestinal tract, lung or bladder. Metastatic ciliary body adenocarcinoma is the most likely diagnosis.

\section{(3) How would you manage this patient?}

The approach to management of this patient is twofold: detection and treatment of the primary cancer and management of the intraocular lesion. Further workup by his primary oncologists, including serum tumour markers and whole body PET/CT scans, failed to demonstrate recurrence or metastasis of the previously treated testicular tumour at other sites or additional primary cancer. The patient underwent radiation to the right eye (40 Gy in 16 fractions).

One month after completion of radiation therapy, the patient complained of significant pain, vision had reduced to 20/200, there was neovascular glaucoma with an intraocular pressure of $28 \mathrm{~mm} \mathrm{Hg}$ and the tumour had progressed. The right eye was enucleated.

Histopathologically, adenocarcinoma involved the ciliary body, anterior surface of the iris (with associated neovascularisation), trabecular meshwork and posterior cornea (fig 2). Histological features of germ cell tumours were not present. Immunoperoxidase stains, performed to identify the possible primary site of this tumour, showed positivity for cytokeratins AE1/3, CK7 and CK20 with negative staining for prostatic specific antigen and thyroid transcription factor- 1 suggesting a primary adenocarcinoma in the gastrointestinal tract (colon, pancreas, stomach, appendix), lung or bladder. ${ }^{1}$

\section{Discussion}

Our case demonstrates the importance of considering intraocular malignancy in the differential diagnosis of a patient with persistent intraocular inflammation who does not respond to appropriate treatment, with a negative laboratory and imaging workup for an underlying inflammatory disease. Meticulous examination is critical in making the correct diagnosis. In our patient, minimal anterior bowing of the peripheral iris and observation of yellow gelatinous deposits in the angle on the slit lamp examination led to a suspicion of an underlying mass lesion which was confirmed by UBM (fig l)..$^{3}$

Intraocular biopsy becomes a necessity when the systemic evaluation fails to offer alternative accessible sites for fine needle aspiration biopsy, such as the lymph nodes, lungs and liver. ${ }^{5}$

Uncommonly, scleritis can be the presenting ocular finding in patients with uveal metastasis. ${ }^{6}$ Other diagnostic possibilities include primary adenocarcinoma of the ciliary body that arises in the pigmented and non-pigmented ciliary epithelium. ${ }^{7}$ Clinically, these tumours mimic melanomas because they appear as slowly growing pigmented circumscribed mass. ${ }^{7}$ Histopathologically, the tumour cells are arranged in a glandular pattern and exhibit prominent basement membrane. ${ }^{7}$

The recommended approach to the management of patients with suspected or proven uveal metastasis is to investigate for the primary tumour as the nature of the primary tumour has direct implications on the diagnosis, treatment and overall prognosis. $^{8}$ In our patient with a history of smoking, adenocarcinoma of the lung is the most likely source of the metastasis. Other sources of primary adenocarcinoma such as gastrointestinal tract or bladder are also being considered. Despite all these efforts, in about 3-5\% of metastatic lesions, the primary tumour may not be identified. ${ }^{9}$ Teratocarcinoma of the testis is a non-seminomatous germ cell tumour that spreads by lymphatics to the retroperitoneal nodes and is not known to metastasise to the uvea. ${ }^{10}$

\section{Final diagnosis}

Iridociliary metastatic adenocarcioma. Primary tumour undetected.

\section{References}

1 Chu PG, Weiss LM. Keratin expression in human tissues and neoplasms. Histopathology 2002;40:403-39

2 Conway RM, Chew T, Golchet P, et al. Ultrasound biomicroscopy: role in diagnosis and management in 130 consecutive patients evaluated for anterior segment tumours. Br J Ophthalmol 2005;89:950-5.

3 Konstantopoulos A, Hossain P, Anderson DF. Recent advances in ophthalmic anterior segment imaging: a new era for ophthalmic diagnosis? $\mathrm{Br} J$ Ophthalmol 2007;91:551-7.

4 Heiligenhaus A, Schilling $M$, Lung $E$, et al. Ultrasound biomicroscopy in scleritis. Ophthalmology 1998;105:527-34.

5 Char D. Intraocular biopsy. In: Singh AD, Damato BE, Pe'er J, et al, eds. Clinical ophthalmic oncology. Philadelphia: Elsevier-Saunders, 2007:334-40.

6 Yap EY, Robertson DM, Buettner H. Scleritis as an initial manifestation of choroidal malignant melanoma. Ophthalmology 1992;99:1693-7.

7 Elizalde J, de la Paz M, Barraquer RI. Tumors of the ciliary pigment epithelium. In: Singh AD, Damato BE, Pe'er J, Murphree AL, Perry J, eds. Clinical Ophthalmic Oncology. Philadelphia: Elsevier-Saunders, 2007:366-371.

8 Bornfeld N. Uveal metastatic tumors. In: Singh AD, Damato BE, Pe'er J, Murphree AL, Perry J, eds. Clinical Ophthalmic Oncology. Philadelphia: ElsevierSaunders, 2007:322-327.

9 Pavlidis N, Fizazi K. Cancer of unknown primary (CUP). Crit Rev Oncol Hematol 2005;54:243-250.

10 Kinkade S. Testicular cancer. Am Fam Physician, 1999;59:2539-2544, 2549-2550. 